\title{
Melanocortin 1 receptor $(M C 1 R)$ gene variants may increase the risk of melanoma in France independently of clinical risk factors and UV exposure
}

\author{
E Matichard, P Verpillat, R Meziani, B Gérard, V Descamps, E Legroux, M Burnouf, G Bertrand, \\ F Bouscarat, A Archimbaud, C Picard, L Ollivaud, N Basset-Seguin, D Kerob, G Lanternier, \\ C Lebbe, B Crickx, B Grandchamp, N Soufir
}

J Med Genet 2004;41:e13 (http://www.jmedgenet.com/cgi/content/full/41/2/e13). doi: 10.1136/jmg.2003.011536

M alignant melanoma (MM) is increasing in most Caucasian populations, the incidence doubling every 10 years. ${ }^{1}$ Multiple phenotypic risk factors, including the number of melanocytic naevi (moles), freckling, dysplastic naevi, propensity to sunburn, and the number of severe sunburn episodes during youth, have been identified in the aetiology and pathogenesis of this disease. ${ }^{2}$

Approximately $10 \%$ of $\mathrm{MM}$ cases occur in kindreds, suggesting hereditary predisposition to melanoma, often in association with the atypical mole syndrome (AMS) phenotype. Germline mutations affecting two highly penetrant genes predisposing to melanoma, $C D K N 2 A$ and $C d k 4$, have been associated with an increased risk for the development of familial cutaneous melanoma. ${ }^{3-6}$ However, these mutations are found in only 30 to $40 \%$ of kindreds, indicating that other genes may predispose to MM.

In addition to the major predisposition to melanoma caused by these genes, polygenic inheritance determining the development of melanoma has been shown to depend upon polymorphisms located on genes controlling different cellular pathways such as DNA repair, ${ }^{7}$ pigmentation, ${ }^{8}$ and reactive oxygen detoxification. ${ }^{9} 10$ Among these, loss of function variants of the human melanocortin 1 receptor gene $(M C 1 R)$, which plays a crucial role in pigmentation, ${ }^{11}{ }^{12}$ seems important in determining MM risk. ${ }^{8}{ }^{13}$

MClR maps to chromosome 16q24.3 and encodes a G protein coupled receptor with seven transmembrane domains expressed on many cell types ${ }^{14}$ including melanocytes. $M C 1 R$ is the receptor of two melanocortin peptides synthesised in the pituitary gland, alpha melanocyte stimulating hormone $(\alpha-\mathrm{MSH})$ and ACTH. These have the same affinity for $M C 1 R$, and are cleavage products of the large precursor peptide propiomelanocortin. Their binding to this receptor activates adenylate cyclase, increases intracellular c-AMP production, then leads to enhanced tyrosinase transcription and traduction, and, ultimately, to production of photoprotective eumelanin and melanocyte proliferation. Regulation of melanogenesis also depends on many paracrine factors, such as agouti signalling protein (ASP), an MCIR antagonist, and endothelin $1 . .^{15}$ Recently, the physiological role of ASP in the regulation of human pigmentation has been suggested. This role may be through the association of a polymorphism, localised 25bp downstream of the TGA termination codon in the non coding exon 4 of the ASP gene, with dark hair and eye colours in a Caucasian population from Pennsylvania. ${ }^{17}$

Recent investigations have demonstrated that $M C 1 R$ is highly polymorphic in the Caucasian population. ${ }^{12}{ }^{18} 19$ About 30 variants have been described, of which nine have been demonstrated to be loss of function variants. ${ }^{2021}$ Some of these variants (Val60Leu, Ile40Thr, Arg142His, Arg151Cys, Argl62Pro, Argl60Trp, and Asp294His) are unable to

\section{Key points}

- Variants causing loss of function of the melanocortin 1 receptor $(M C 1 R)$ gene, a key control of human skin pigmentation, increase the risk of malignant melanoma (MM) in Queensland, the UK, and the Netherlands.

- The prevalence and role of MCIR variants in genetic predisposition to $M M$ are not known in the French population; 108 patients with MM and 105 controls were investigated for these variants. The patients were divided into two categories: those suspected of genetic predisposition to MM but without CDKN2A or Cdk4 germline mutations (79), and those with sporadic simple melanomas (29).

- MCIR variants causing loss of function were present in $68 \%$ of patients $v 31 \%$ of controls $(p<0.0001)$, confirming the role of MCIR in genetic predisposition to $M M$ in the French population. Three frequent variants were significantly associated with $M M$ risk: Val60Leu, Arg151Cys, and Arg160Trp. The risk persisted after stratification on clinical risk factors (skin colour and type, hair and eye colour, solar lentigines, and naevus count) and UV exposure parameters.

- The data showed that MCIR variants causing loss of function are a strong and independent melanoma risk factor in France.

- Assessment of MCIR status as well as of clinical risk factors could be useful in the identification of high risk groups which could then be targeted for prevention.

stimulate cAMP production as strongly as the wild type receptor in response to $\alpha$-MSH stimulation, ${ }^{22-26}$ whereas others (Val122Met) demonstrate a decreased $\alpha$-MSH binding affinity. ${ }^{25}$ Three $M C 1 R$ variants alleles (Arg151Cys, Arg 160Trp, and Asp294His) have been shown to be associated with the red hair and fair skin phenotype (RHC). RHC is characterised by fair pigmentation (fair skin, red hair, and freckles), and by sun sensitivity (poor tanning response and

Abbreviations: $M M$, malignant melanoma; FAM, familial melanoma; MPM, multiple primary melanoma; NPIM, non-photo induced melanoma; $\mathrm{ALM}$, acral lentiginous melanoma; $M C 1 R$, melanocortin 1 receptor; $\alpha-M S H$, alpha melanocyte stimulating hormone; PAR, population attributable risk; AMS, atypical mole syndrome; ASP, agouti signalling protein; RHC, red hair characteristics; NMSC, non-melanoma skin cancer 
solar lentigines). ${ }^{11} 1218192728$ In addition, seven other alleles (Val60Leu, 86insA, Asp84Glu, Arg142His, Ile155Thr, 537insC, and His260Pro) may be statistically considered full or partial RHC causing alleles, as shown by genetic associations in populations or through inheritance of phenotype in families. ${ }^{29}$

$M C 1 R$ variants have also been found to be associated with both MM and non-melanoma skin cancer (NMSC) risks. ${ }^{80-34}$ Furthermore, MCIR variants appear to increase the penetrance of $\mathrm{pl} 6^{\mathrm{INK} 4 \mathrm{~A}}$ mutations in melanoma prone families. ${ }^{35} 36$

Despite these data, several questions remain to be elucidated. First, $M C 1 R$ studies have been carried out only in Caucasian populations with RHC originating from North Europe; the relationship between $M C 1 R$ variants and MM in other populations is still unknown. Secondly, at present it is not clear whether the MM risk attributed to $M C l R$ variants is distinct from its effects on pigmentation characteristics. ${ }^{8}$ Thirdly, the prevalence of $M C l R$ variants in patients with a suspected hereditary predisposition to MM has only been investigated in Australian melanoma families. ${ }^{8}$ Finally, the role of $M C 1 R$ variants regarding UV irradiation has not yet been examined.

Therefore, we sought to examine the association between $M C 1 R$ variants and MM risk in a French case control study, by comparing individuals who had histologically confirmed MM with controls without personal or family history of skin cancer. Additional specific aims of this study were to assess the prevalence of $M C I R$ variants among patients suspected of genetic predisposition to MM, divided into subgroups: familial melanoma (FAM), multiple primary melanoma (MPM), melanoma associated with another cancer, melanoma arising before the age of 25 years, and non-photo induced melanoma (NPIM). The risk for MM from MCIR variants was estimated after adjustment for clinical risk factors (naevi count, skin types I and II, eye colour, fair hair and skin colours, lentigines) and UV exposure (particularly severe sunburns and high intermittent exposure).

\section{MATERIALS AND METHODS Study population}

We recruited 108 patients with MM and 105 controls.

Of the MM patients, $29 \%$ were incident cases and $71 \%$ were prevalent cases. The median time between diagnosis and genetic investigation was 44.6 months. All participants were Caucasian and attended dermatology departments in one of three hospitals in Paris (France), namely Bichat Claude-Bernard, Percy, and Saint-Louis Hospitals. The study population consisted of patients aged from 20 to 80 years with histologically proved MM.

A total of 79 patients sharing features that might underlie genetic predisposition to $\mathrm{MM}$, but without germline mutations in the $C D K N 2 A$ or $C d k 4$ genes, were enrolled according to five different criteria:

- sporadic multiple primary melanomas (MPMs), with at least $2 \mathrm{MMs}$ at different sites

- familial melanomas (FAMs), with at least two cases of MM in first or second degree relatives

- MMs associated with another cancer

- MMs diagnosed before the age of 25 years

- MMs considered to be non-photo induced (NPIMs).

NPIMs included melanomas located on non-photo exposed sites, and subungual and acral lentiginous melanomas (ALMs). ALMs are considered to be a particular subtype of MM because, in contrast to other subtypes, they exclusively involve acral skin which is rarely exposed to sunlight, thus suggesting that ultraviolet irradiation is not a major factor in their development. ${ }^{37}$ Six patients who carried CDKN2A germline mutations were not included (three with FAMs, one with MPM, one with MM before the age of 25 years, and one with NPIM).

Another group of 29 "simple" melanoma patients without any of the above criteria was also enrolled. Patients were not included if immune depressed (HIV or transplantation), or suffering from a genodermatosis predisposing to skin cancer (albinism, Gorlin's syndrome, or xeroderma pigmentosum).

A control group, without any personal or familial history of skin cancer, was enrolled for the comparison of MCIR allele frequencies. The subjects, aged from 20 to 80 years, were recruited in the same hospitals, as representative of the same demographic area as the patients with MM. Information concerning personal and familial details (parents and grandparents) and country of birth was also recorded. NonCaucasians were not included in the study.

The Medical Ethics Committee (CCPPRB) approved the study protocol. Informed consent was obtained from all subjects.

\section{Collection of data on risk factors for MM}

All participants attended for a standardised personal interview and a total skin examination with a dermatologist, to collect data which was entered onto a preprinted examination sheet.

Information concerning skin (recorded as being either dark, medium, or light), eyes (classified as dark (brown) or light (blue, green, or grey)), and original hair colour (classified as red, blond, light brown, dark brown, or black) was collected. We also recorded naevus body count $(<$ or $\geqslant 50$ naevi); presence of solar lentigines; and presence of AMS. AMS was recorded if 50 or more naevi were found, at least three being clinically atypical: $6 \mathrm{~mm}$ or more in diameter, variable pigmentation, and indistinct and irregular outline). ${ }^{39}$ Skin type was assessed according to TB Fitzpatrick's classification (1988) as follows:

- I, always burns and never tans

- II, always burns and then tans

- III, always tans and sometimes burns

- IV, always tans and never burns.

In addition, for the MM group, location of lesions, age at diagnosis, and histopathological data were collected.

\section{Assessment of UV exposure}

A questionnaire was used to determine the history of severe sunburns before and after the age of 15 years, defined as erythema for more than 48 hours or blistering (scored yes/ no). Intermittent sun exposure before and after the age of 15 years was defined as UV exposure during the holidays: beachside or sunny vacations were scored as strong exposures. Chronic exposition was evaluated throughout the year, and was scored as nil, light, medium, or strong. Sunscreen use was noted as never, sometimes, or always.

\section{Detection of $M C 1 R$ variants}

Genomic DNA was isolated from peripheral blood leukocytes of all participants by routine methods. The MCIR coding sequence was amplified by PCR with two overlapping couples of primers: $M C 1 R-\mathrm{F} 1-5^{\prime}-\mathrm{CAG}$ CAC CAT GAA CTA AGC AGG ACA CCT G - $3^{\prime}$ and $M C I R I-I R-5^{\prime}$-CCA GCA TAG CCA GGA AGA AGA CCA CGA G -3', and $M C 1 R$-F2-5'-TGG GTG GCC AGT GTC GTC TTC AGC A - $3^{\prime}$ and MC1R2-R-5'-AAG GGT CCG CGC TTC AAC ACT TTC AGA G -3', (respective sizes of PCR products, 671 and $610 \mathrm{bp}$ ). The PCR reaction mixture comprised $150 \mathrm{ng}$ genomic template DNA, $5 \mu \mathrm{l}$ 10X PCR buffer, $25 \mathrm{mM} \mathrm{MgCl}_{2}, 5 \mu \mathrm{M}$ each of dGTP, dTTP, dATP, and dCTP, 22.5 pmol each of PCR primer, and 2 U AmpliTaq (Perkin Elmer; Courtabocuf cedex, France), in a total volume 
of $50 \mu \mathrm{l}$. Samples were denatured for six minutes at $96^{\circ} \mathrm{C}$, and passed through 35 cycles of amplification, consisting of 30 seconds of denaturation at $95^{\circ} \mathrm{C}, 30$ seconds of primer annealing at $60^{\circ} \mathrm{C}$, one minute of elongation at $72^{\circ} \mathrm{C}$, and final elongation for three minutes at $72^{\circ} \mathrm{C}$. The amplifications were carried out in $0.5 \mathrm{ml}$ tubes (Perkin Elmer).

\section{Sequence analysis}

DNA samples for sequencing were obtained by PCR as described above. Sequence analysis was performed on an ABI-Prism 3100 automated DNA sequencer using 10 ng PCR purified products and Big-Dye Terminator Cycle Sequencing kits (Perkin Elmer), according to the manufacturer's instructions.

\section{Statistical analyses}

Statistical analyses were carried out using SAS software release 8.2 (SAS Institute, Cary, NC, USA). ANOVA or $\chi^{2}$ analysis (Fisher's exact test when necessary) were used to compare clinical and genetic characteristics, as well as UV exposure parameters, between MM patients and controls.

For clinical analysis, the usual MM risk factors were compared between cases and controls.

For genetic analysis, the only MCIR polymorphisms retained were:

- those previously shown to be loss of function variants by functional studies ${ }^{22-26} 4147$

- those associated with MM risk ${ }^{813} 30$

- those associated with RHC phenotype ${ }^{29}$

- those predicted to be possibly damaging by the Polyphen informatics program (http://tux.EMBL-Heidelberg.DE/ ramensky/).

This approach was conservative and allowed us to include all patients and controls for the analysis. Pairwise linkage disequilibrium between the different MCIR polymorphisms was also studied, using the EH (Estimation of Haplotypes) program. First, univariate analyses were used to compare genetic risk factors ( $M C 1 R$ genotype) between MM patients and controls. Secondly, multiple logistic regression analysis (using a stepwise procedure) was performed to take into account potential confounders among clinical risk factors, such as skin type, eye and hair colour, number of naevi, AMS, dorsal lentigines, and UV exposure. Odds ratios (ORs) were calculated with $95 \%$ confidence intervals. All significance levels reported were two-sided and set at $\mathrm{p}<0.05$.

Comparisons were carried out of age at onset between:

- MM patients carrying $M C 1 R$ variants $v$ MM patients that do not carry $M C l R$ variants

- and MM patients carrying MCIR variants $v$ MM patients carrying germline $C D K N 2 A$ mutations.

Comparisons were performed using the ANOVA test.

The percentage population attributable risk (PAR\%) associated with the most frequent MCIR variants was calculated as previously described. ${ }^{48}$

\section{RESULTS}

\section{Composition of patient population}

The final series for analysis comprised 213 participants: 108 patients with MM and 105 controls. The percentage of individuals that were born in France, with both parents born in France, was $70 \%$ in the patients' group, and $60 \%$ in the control group. Other places of birth included European countries (Switzerland, Germany, Greece, Spain, Portugal, Italy, Slovenia, Croatia, and Turkey) or the Maghreb (Tunisia, Algeria, Morocco). The 108 patients were categorised into two different groups.
The first group was composed of 79 patients suspected of genetic predisposition to $\mathrm{MM}$, including the following pathologies:

- 18 FAMs, three of which harboured the typical AMS phenotype

- 17 sporadic MPMs

- 11 MMs with an additional cancer (two mammary adenocarcinomas, one papillary thyroid carcinoma, one prostate carcinoma, one uterine carcinoma, one carcinoma of the colon, four non-melanoma skin cancers, one meningioma)

- 20 MMs diagnosed before the age of 25 years

- 14 NPIMs (one on the anus, two on the colon, four on the buttocks, two on the genitals, one on the scalp, and four ALMs (three subungual and one on the sole of the foot)).

The second group comprised 28 simple sporadic MMs without any of the above pathologies.

\section{Clinical characteristics}

The clinical characteristics of all patients with MM and of control subjects are summarised in table 1 . The strongest risk factors identified for $\mathrm{MM}$ were a mole count $>50$ $(p<0.0001)$, presence of AMS $(p=0.0004)$, presence of fair skin $(p<0.0001)$, and dorsal lentigines $(p<0.0001)$. Other pigmentation characteristics (light eye and hair colours), as well as severe sunburns before and after the age of 15 years, were lower predictors of MM risk (table 1). In this sample, skin type I or II, although more frequent in MM patients, was not significantly associated with MM risk.

\section{Ultraviolet exposure}

Univariate analysis showed that severe sunburns before and after the age of 15 years ( $p=0.03$ and 0.05 , respectively), intermittent exposure during holidays after the age of 15 years $(p=0.03)$, and absence of sunscreen use $(p=0.04)$ were associated with MM risk, as in previous studies (table 1). Multiple analyses, after controlling for other variables, confirmed this association for two parametersabsence of sunscreen use, and severe sunburns after the age of 15 years (data not shown). In this study, cumulative sun exposure, as determined by chronic exposure during the week during occupational activities, was not identified as a risk factor for MM (data not shown).

\section{Frequency of $M C I R$ variants and effect on MM risk}

We identified 16 non-synonymous $M C 1 R$ variant alleles, of which 12 have shown experimental and/or predicted loss of function effects, and/or have been previously associated with MM risk and/or RHC (see Materials and Methods and table 2). Among these, two previously unreported MClR variants (Argl42Cys and Tyr298His) were observed, each in one (differing) MM patient.

Functional variants were much more common in the MM group, with $73 / 108$ patients $(67.6 \%)$ carrying at least one $M C 1 R$ variant, compared with only 33/105 control subjects $(31.4 \%)(\mathrm{p}<0.0001$, table 3$)$. In addition, there was a gene dosage effect of MCIR variant on MM risk (ORs, respectively, 4.3 for one variant and 6.78 for two variants; Mantel Haenszel trend test $\mathrm{p}<0.0001$ ).

Not all individual MCIR alleles conferred the same MM risk (table 2). Only three variants (Val60Leu, Arg151Cys, and Argl60Trp) were significantly more frequent in the MM group, with the strongest risk being for Arg 151Cys (OR 6.26). The nine other MClR variants (Vall22Met, Argl42His, Arg 142Cys, Ile155Thr, ins86, Ser83Pro, Asp84Glu, Asp294His, and Tyr298His) were not individually associated with MM 
Table 1 Clinical characteristics and number of patients with melanoma and of controls

\begin{tabular}{|c|c|c|c|c|}
\hline & $\begin{array}{l}\text { Melanoma } \\
(108)\end{array}$ & $\begin{array}{l}\text { Controls } \\
\text { (105) }\end{array}$ & $\mathbf{p}$ & OR \\
\hline \multicolumn{5}{|l|}{ Gender } \\
\hline Women & $64.8(70)$ & $54.3(57)$ & - & Reference \\
\hline Men & $35.2(38)$ & $45.7(48)$ & 0.12 & $0.6(0.4-1.1)$ \\
\hline \multicolumn{5}{|l|}{$\begin{array}{l}\text { Mean age at } \\
\text { onset (SD) }\end{array}$} \\
\hline and range & $\begin{array}{l}44.5 \pm 17.3 \\
(14-77)\end{array}$ & *51 (20-93) & 0.008 & NA \\
\hline \multicolumn{5}{|l|}{ Skin type } \\
\hline III/IV & $52.0(53)$ & $59.0(62)$ & - & Reference \\
\hline I/II & $48.0(49)$ & $41.0(43)$ & 0.31 & $1.3(0.8-2.4)$ \\
\hline \multicolumn{5}{|l|}{ Skin colour } \\
\hline Dark & $6.9(7)$ & $27.6(29)$ & - & Reference \\
\hline \multicolumn{5}{|c|}{ Hair colour } \\
\hline $\begin{array}{l}\text { Dark or dark } \\
\text { brown }\end{array}$ & $52.0(51)$ & $72.4(76)$ & - & Reference \\
\hline $\begin{array}{l}\text { Blond, light } \\
\text { brown, red } \\
\text { Eye colour }\end{array}$ & $48.0(47)$ & $27.6(29)$ & 0.0028 & $2.4(1.3-4.3)$ \\
\hline Dark & $46.9(46)$ & $67.6(71)$ & - & Reference \\
\hline Light & $53.1(52)$ & $32.4(34)$ & 0.003 & $3.4(1.3-4.2)$ \\
\hline \multicolumn{5}{|l|}{ Total naevi } \\
\hline$\leqslant 50$ & $53.5(54)$ & $93.3(98)$ & - & Reference \\
\hline$>50$ & $46.5(47)$ & $6.7(7)$ & $<0.0001$ & $12.2(5.2-28.8)$ \\
\hline \multicolumn{5}{|c|}{$\begin{array}{l}\text { Atypical mole } \\
\text { syndrome }\end{array}$} \\
\hline No & $80.6(83)$ & $96.2(101)$ & - & Reference \\
\hline Yes & $19.4(20)$ & $3.8(4)$ & 0.0004 & $6.1(2.0-18.5)$ \\
\hline \multicolumn{5}{|l|}{ Lentigines } \\
\hline No & $34.4(32)$ & $67.0(69)$ & - & Reference \\
\hline Yes & $65.6(61)$ & $33.0(34)$ & $<0.0001$ & $3.9(2.1-7.0)$ \\
\hline \multicolumn{5}{|c|}{$\begin{array}{l}\text { Sunburns with } \\
\text { blistering at } \\
<15 \text { years of } \\
\text { age }\end{array}$} \\
\hline No & $50.0(49)$ & $64.8(68)$ & - & Reference \\
\hline Yes & $50.0(49)$ & 35.2 (37) & 0.03 & $1.8(1.0-3.2)$ \\
\hline \multicolumn{5}{|c|}{$\begin{array}{l}\text { Sunburns with } \\
\text { blistering at } \\
>15 \text { years of } \\
\text { age }\end{array}$} \\
\hline No & $41.4(41)$ & $55.2(58)$ & - & Reference \\
\hline Yes & $58.6(58)$ & $44.8(47)$ & 0.05 & $1.7(1.0-3.0)$ \\
\hline \multicolumn{5}{|c|}{$\begin{array}{l}\text { Holiday UV } \\
\text { exposure at } \\
<15 \text { years of } \\
\text { age }\end{array}$} \\
\hline Low & 11 & 21 & - & $2.0(0.9-4.4)$ \\
\hline High & 87 & 84 & 0.09 & Reference \\
\hline \multicolumn{5}{|c|}{$\begin{array}{l}\text { Holiday UV } \\
\text { exposure at } \\
>15 \text { years of } \\
\text { age }\end{array}$} \\
\hline Low & 10 & 22 & - & Reference \\
\hline High & 89 & 83 & 0.03 & $2.4(1.1-5.3)$ \\
\hline \multicolumn{5}{|c|}{ Sunscreen use } \\
\hline Yes & 15 & 28 & - & Reference \\
\hline No & 75 & 68 & 0.04 & $2.1(1.0-4.2)$ \\
\hline
\end{tabular}

NA, not applicable, ${ }^{*}$, median age; OR, odds ratios with $95 \%$ confidence intervals.

risk, although it should be noted that for Asp294His statistical results were nearly significant $(\mathrm{p}=0.058)$.

$M C 1 R$ variants allelic frequency observed in incident cases (genetic investigation within one year after MM diagnosis) was not statistically different from that observed in prevalent cases $(36.8 \% \vee 45 \% ; p=0.25$, Fisher's exact test).

The PAR\% of MM associated with the main MCIR variants is indicated in table 4. Val60Leu has the highest PAR, followed by Arg151Cys and Argl60Trp.

\section{Effect of MCIR on the age of onset of melanoma}

No effect of MCIR genotype on the age of onset of melanoma was observed: median age at diagnosis of MM patient carriers
Table 2 Allelic frequencies of $M C 1 R$ variants in patients with melanoma and in control subjects

\begin{tabular}{|c|c|c|c|c|}
\hline & $\begin{array}{l}\text { Patients } \\
\text { (n = 216) }\end{array}$ & $\begin{array}{l}\text { Controls } \\
(n=210)\end{array}$ & $\begin{array}{l}\text { Odds ratios } \\
(95 \% \mathrm{Cl})\end{array}$ & $\mathbf{p}$ \\
\hline \multirow{2}{*}{\multicolumn{5}{|c|}{ MCIR variants type 1}} \\
\hline & & & & \\
\hline Val92Met & $5.6(12)$ & $7.1(15)$ & - & - \\
\hline Arg163Gln & $4.6(10)$ & $2.4(5)$ & - & - \\
\hline Thr95Met & $1.4(3)$ & $0.9(2)$ & - & - \\
\hline Val180lle & $0(0)$ & 0.5 (1) & - & - \\
\hline Total MCIR wt & $57.9(125)$ & $85.7(180)$ & 1.0 & Reference \\
\hline \multicolumn{5}{|c|}{$M C I R$ variants type 2} \\
\hline Arg151Cys†§†† & $8.3(18)$ & $1.9(4)$ & $\begin{array}{l}6.48 \\
(2.14-19.61)\end{array}$ & 0.0002 \\
\hline Arg160Trp†§ & $7.9(17)$ & $2.4(5)$ & $\begin{array}{l}4.73 \\
(1.70-13.18)\end{array}$ & 0.0013 \\
\hline Val60leut & $16.7(36)$ & $6.2(13)$ & $\begin{array}{l}3.99 \\
(2.03-7.82)\end{array}$ & $<0.0001$ \\
\hline Asp294His †£†† & $3.7(8)$ & $1.4(3)$ & $\begin{array}{l}3.84 \\
(0.90-22.81)\end{array}$ & $0.058^{*}$ \\
\hline Argl $42 \mathrm{His} \dagger \ddagger \dagger \dagger$ & $1.4(3)$ & $0(0)$ & NA & $0.07^{*}$ \\
\hline Argl 142 Cystt & 0.5 (1) & $0(0)$ & NA & 0.41 \\
\hline lle155Thrt† & $0.9(2)$ & $0.9(2)$ & $\begin{array}{l}1.44 \\
(0.10-20.08)\end{array}$ & 1.0 \\
\hline Ser83Prot† & $0.5(1)$ & $0(0)$ & NA & 0.41 \\
\hline Asp84Glust† & $1.4(3)$ & $0.9(2)$ & $\begin{array}{l}2.16 \\
(0.24-26.14)\end{array}$ & $0.41^{*}$ \\
\hline Tyr298Hist† & $0.5(1)$ & $0(0)$ & NA & 0.41 \\
\hline Val122Meł & $0(0)$ & $0.5(1)$ & NA & $1.0^{*}$ \\
\hline Ins 86¥¥ & 0.5 (1) & $0(0)$ & NA & 0.41 \\
\hline Total variants type 2 & 42.1 (91) & $14.3(30)$ & $\begin{array}{l}4.37 \\
(2.73-7.00)\end{array}$ & $<0.0001$ \\
\hline
\end{tabular}

n, number; NA, not applicable.

ORs are indicated with $95 \%$ confidence interval (CI).

Type 1 variants may not modify MCIR function, as these variants have not been previously associated with melanoma nor tested in functional assays (see statistical analyses in Material and Methods). These variants are pooled with the MCIR consensus sequence and considered as wild type in statistical analyses.

Type 2 variants have been shown to result in diminished MCIR function, and/or to be associated with fair pigmentation characteristics $(\mathrm{RHC}){ }^{29}$ and/or to be strongly associated with the risk of melanoma in previous studies.

*Fisher's exact test.

TMC1R variants unable to stimulate CAMP production as strongly as the wild type receptor in response to alpha melanocyte stimulating hormone $(\alpha-M S H){ }^{2-26}$

$\pm M C 1 R$ variants showing a decreased $\alpha-M S H$ binding affinity. ${ }^{25}$ $\S M C 1 R$ variants previously shown to be associated with melanoma risk. $^{8} 13$ 30

- MCIR variants previously shown to be associated with the RHC phenotype. $^{29}$

$†+M C I R$ variants predicted to be damaging (deducted from the Polyphen program).

of MCIR variants was $46.17 v 39.88$ years for the MM group without variant $(\mathrm{p}=0.087$; standard deviation $17.11 \mathrm{v} 17.17$ using the ANOVA test). Median age at diagnosis was lower for patients carrying $C D K N 2 A$ mutations (35.5 years, range 23-64), but this was not statistically significant $(\mathrm{p}=0.23$, ANOVA test), presumably because of the small number of CDKN2A mutated patients studied.

\section{Distribution of MCIR variants in the different MM subgroups}

Table 5 shows the distribution of $M C 1 R$ variants among the five MM subgroups. The highest MCIR allelic frequencies were observed in FAM and MPM subgroups (50\%), whereas the lowest were observed in the NPIM group (28.5\%). However, there was no statistical difference in $M C 1 R$ allelic frequencies between the different subgroups $(\mathrm{p}=$ 0.37 ), or between the simple MM group and the group with more stringent genetic criteria (FAM, MPM, NPIM, $\mathrm{MM}<25$ years of age, MM associated with another cancer) $(\mathrm{p}=0.35)$. 
Table $3 M C 1 R$ genotype in patients with melanoma and in control subjects; association of MCIR variants with the risk (odds ratios) of $M M$

\begin{tabular}{llcll}
\hline $\begin{array}{l}\text { MCIR } \\
\text { genotype }\end{array}$ & $\begin{array}{l}\text { Patients } \\
(\mathbf{n}=108)\end{array}$ & $\begin{array}{c}\text { Controls } \\
(\mathbf{n}=105)\end{array}$ & $\mathbf{p}$ & Odds ratios \\
\hline Wt/Wt & $31.5(34)$ & $68.6(72)$ & & Reference \\
Wt/V & $52.8(57)$ & $26.7(28)$ & $<.0001$ & $4.3(2.34-7.93)$ \\
V/V & $14.8(16)$ & $4.7(5)$ & $<.0002$ & $6.78(2.29-20.03)$ \\
\hline
\end{tabular}

n, number.

$\mathrm{W} t$ represents the wild type allele; $V$ represents variant alleles.

Odds ratios (indicated with $95 \%$ confidence intervals) compare $\mathrm{Wt}_{\mathrm{t}} / \mathrm{V}$ (heterozygotes) and V/V (two functional variants) with $\mathrm{Wt}_{t} / \mathrm{Wt}_{\mathrm{t}}$.

\section{Effect of $M C 1 R$ on pigmentation characteristics}

In order to study the effects of $M C I R$ on pigmentation characteristics and naevus count, cases and controls were grouped together. Statistical analysis confirmed previous observations, in that $M C I R$ variants were significantly associated with light hair colour (red, blond, light brown, $\mathrm{p}<0.0001)$; skin type I-II ( $\mathrm{p}=0.0015)$; solar lentigines $(\mathrm{p}=0.0019)$; and either light or medium skin colour (Mantel Haenszel trend test, $\mathrm{p}=0.047$ ). In addition, $M C 1 R$ variants were also associated with light eye colour $(\mathrm{p}=$ $0.027)$. Conversely, $M C l R$ variants were not associated with naevus count ( $\mathrm{p}=0.19)$ (data not shown).

\section{Persistence of $M M$ risk after stratification on pigmentation characteristics and UV exposure}

Clinical and epidemiological data indicated further investigation of the association between MCIR functional variants and MM risk. Table 6 shows the significant persistence of MM risk according to $M C I R$ variants after stratification for the different melanoma associated clinical risk factors (skin types I or II, medium or light skin, red or light hair, light eye colour). These results strongly suggest that $M C 1 R$ variants are an independent risk factor for the development of MM.

In addition, $M C I R$ MM risk also persisted after stratification on classical UV exposure risk factors (severe sunburns and high intermittent UV exposure, both before and after the age of 15 years), suggesting that MCIR confers an MM risk independently of UV exposure (table 6). Interestingly, in multiple logistic regression analyses, which take into account all these potential confounders, the presence of $M C 1 R$ variants was the second most important MM risk factor risk (odds ratio 4.52, 95\% confidence interval 2.15-9.52), after a high naevus count (odds ratio 12.66, 95\% confidence interval 4.81-33.33, table 7).

\section{DISCUSSION}

Numerous studies have shown that MCIR is highly polymorphic in the Caucasian population in the British Isles, Holland, and Australia, ${ }^{12} 182842-44$ and that some $M C 1 R$ variants are associated with the risk of MM and nonmelanoma skin cancer in populations of Celtic and/or Germanic origin (Australia, Scotland, Ireland, and the Netherlands). ${ }^{8} 133345$

In this study, we have shown a strong association between functional MCIR variants and MM in the French population, which is of a different geographical origin. This confirms and highlights the role of $M C 1 R$ in genetic predisposition to MM.

$M C I R$ variants were previously found to be associated with RHC $^{18} 192728$ and sun sensitivity. ${ }^{46}$ In our study, MClR functional alleles were also associated with medium or light skin colour, skin types I and II, fair hair colour (red, blond, and light brown), and presence of solar lentigines, further demonstrating that $M C 1 R$ plays a crucial role in human pigmentation and response to UV radiation in a French
Table 4 Percentage population attributable risk associated with the most frequent $M C 1 R$ variants

\begin{tabular}{lcl}
\hline Variant & *PAR (\%) & $\mathrm{Cl}(95 \%)$ \\
\hline Val60Leu & 10.18 & $(3.93 ; 16.03)$ \\
Arg151Cys & 6.55 & $(2.31 ; 10.61)$ \\
Arg160Trp & 5.62 & $(1.35 ; 9.72)$ \\
Asp294His & 2.31 & $(0.75 ; 5.27)$ \\
\hline
\end{tabular}

*The percentage population attributable risk (PAR\%) associated with the four frequent $M C 1 R$ variants was calculated as previously described, ${ }^{48}$ and is indicated with $95 \%$ confidence intervals (CI).

Table $5 M C 1 R$ variants allelic frequencies among the different subgroups

\begin{tabular}{|c|c|c|c|}
\hline \multirow{2}{*}{$\begin{array}{l}\text { Subgroup } \\
1\end{array}$} & \multicolumn{2}{|c|}{$M C I R$ variants } & \multirow{2}{*}{$\begin{array}{l}\text { Allelic } \\
\text { frequency }\end{array}$} \\
\hline & Present* & Absent & \\
\hline $1(n=18)$ & 15 & 3 & $50 \%$ \\
\hline $2(n=17)$ & 14 & 3 & $50 \%$ \\
\hline $3(n=20)$ & 12 & 8 & $32 \%$ \\
\hline $4(n=11)$ & 8 & 3 & $41 \%$ \\
\hline $5(n=14)$ & 8 & 6 & $28.5 \%$ \\
\hline $6(n=28)$ & 20 & 8 & $46 \%$ \\
\hline Total $(n=108)$ & 77 & 31 & $41 \%$ \\
\hline
\end{tabular}

n, number.

1 , familial melanoma; 2 , multiple primary melanoma; 3 , melanoma before the age of 25 years; 4 , melanoma associated with another cancer; 5, non-photo induced melanoma; 6, simple melanoma.

${ }^{*}$, number of patients carrying at least one $M C I R$ variant described in table 2.

population. However, it should be noted that the individual allelic frequencies of the main $M C I R$ functional variants in our control population (table 2) were much lower than those reported in previous studies. ${ }^{8} 1345$ This difference in allele frequencies might due to the particular characteristics of the French population, which has a darker complexion and a different genetic ancestry from the other populations studied (that were mainly of Celtic origin). In addition, we observed a very low $M C 1 R$ variant frequency in control subjects with skin type I/II (23\%) (table 6). As it has been shown that pigmentation is a complex process under the control of at least 50 different loci in mice, ${ }^{49}$ it seems reasonable to assume that other polymorphisms (localised in pigmentation genes different from $M C 1 R$ ) also play an important role in the genetic control of human pigmentation and could explain our result.

Two large studies reported that $M C l R$ variants increase MM risk, with a mean odds ratio varying between 2 and 4 , depending on whether one or two variants were present. ${ }^{81}$ It is difficult to compare our data with the previous studies, as the coding sequence of $M C l R$ was completely examined in only one of them. ${ }^{13}$ However, we confirmed the effect of $M C 1 R$ variants on MM risk, increasing the risk by a factor of four when one variant was present, and by seven when two variants were present (table 3 ). The $M C I R$ related MM risks were nearly the double those previously reported, ${ }^{813}$ a result most likely due to an increased frequency of the MClR consensus genotype in our control population.

Separate analyses of individual $M C 1 R$ variant alleles showed that three variant alleles (all of which are common) were significantly associated with an increased risk of MM (table 2). Arg 151Cys and Arg 160Trp showed the highest risk, as in previous studies. ${ }^{81}$ However, Val60Leu, which was not or was weakly associated with MM risk in Australia and the Netherlands, ${ }^{81}$ appeared here to be the most frequent variant and to be associated with an important MM risk (odds ratio $3.99,95 \%$ confidence interval $2.03-7.82$ ). Two 


\begin{tabular}{|c|c|c|c|c|c|c|c|}
\hline Risk factor & & Allele & ${ }^{*}$ Cases & ${ }^{*}$ Controls & p & OR & $95 \% \mathrm{Cl}$ \\
\hline \multirow[t]{8}{*}{ Skin type } & \multirow[t]{4}{*}{$1 / I 1$} & Total & 49 & 43 & - & - & - \\
\hline & & $W_{t} / W_{t}$ & $22(11)$ & $67(29)$ & - & Reference & - \\
\hline & & $W_{t} / V$ & $51(25)$ & $23(10)$ & 0.0001 & 6.59 & $2.40-18.09$ \\
\hline & & $V / V$ & 27 (13) & $9(4)$ & 0.0006 & 8.57 & $2.29-32.01$ \\
\hline & \multirow[t]{4}{*}{ III/IV } & Total & 52 & 62 & - & - & - \\
\hline & & $W_{t} / W_{t}$ & $42(22)$ & $69(43)$ & - & Reference & - \\
\hline & & $W_{t} / V$ & $52(27)$ & $29(18)$ & 0.007 & 2.93 & $1.33-6.43$ \\
\hline & & $V / V$ & $6(3)$ & $2(1)$ & $0.13 \$$ & 5.86 & $0.43-314.79$ \\
\hline \multirow{4}{*}{ Skin colour } & \multirow{4}{*}{ Light/medium } & Total & 93 & 76 & - & - & - \\
\hline & & $W_{t} / W_{t}$ & $30(28)$ & 71 (54) & - & Reference & - \\
\hline & & $W_{t} / V$ & $53(49)$ & $24(18)$ & $<0.0001$ & 5.25 & $2.59-10.65$ \\
\hline & & $\mathrm{V} / \mathrm{V}$ & $17(16)$ & $5(4)$ & 0.0002 & 7.71 & $2.35-25.28$ \\
\hline \multirow{8}{*}{ Eye colour } & \multirow{4}{*}{ Light } & Total & 52 & 34 & - & - & - \\
\hline & & $W_{t} / W_{t}$ & 37 (19) & 79 (27) & - & Reference & - \\
\hline & & $W_{t} / V$ & $42(22)$ & $12(4)$ & 0.0004 & 7.81 & $2.32-26.38$ \\
\hline & & $V / V$ & 21 (11) & 9 (3) & 0.015 & 5.21 & $1.28-21.24$ \\
\hline & \multirow{4}{*}{ Dark } & Total & 45 & 71 & - & - & - \\
\hline & & $W_{t} / W_{t}$ & 31 (14) & $63(45)$ & - & Reference & - \\
\hline & & $W_{t} / V$ & $58(26)$ & 34 (24) & 0.002 & 3.48 & $1.54-7.88$ \\
\hline & & $\mathrm{V} / \mathrm{V}$ & $11(5)$ & $3(2)$ & $0.018 \$$ & 8.04 & $1.12-89.57$ \\
\hline \multirow{8}{*}{ Hair colour } & \multirow{4}{*}{ Red/blond/light brown } & Total & 47 & 29 & - & - & - \\
\hline & & $W_{t} / W_{t}$ & $28(13)$ & $66(19)$ & - & Reference & - \\
\hline & & $W_{t} / V$ & 45 (21) & $21(6)$ & 0.004 & 5.12 & $1.62-16.14$ \\
\hline & & $\mathrm{V} / \mathrm{V}$ & 28 (13) & $14(4)$ & 0.017 & 4.75 & $1.26-17.86$ \\
\hline & \multirow{4}{*}{ Dark brown/black } & Total & 50 & 76 & - & - & - \\
\hline & & $W_{t} / W_{t}$ & $40(20)$ & $70(53)$ & - & Reference & - \\
\hline & & $W_{t} / V$ & 54 (27) & $29(22)$ & 0.002 & 3.25 & $1.52-6.97$ \\
\hline & & $\mathrm{V} / \mathrm{V}$ & $6(3)$ & $1(1)$ & $0.077 \$$ & 7.95 & $0.58-424.97$ \\
\hline \multirow{4}{*}{ Naevus count } & \multirow{4}{*}{$\leqslant 50$} & Total & 53 & 98 & - & - & - \\
\hline & & $W_{t} / W_{t}$ & $30(16)$ & $68(67)$ & - & Reference & - \\
\hline & & $W_{t} / \mathrm{V}$ & $53(28)$ & $28(27)$ & $<0.0001$ & 4.34 & $2.03-9.28$ \\
\hline & & $\mathrm{V} / \mathrm{V}$ & $17(9)$ & $4(4)$ & $0.0005 \$$ & 9.42 & $2.21-45.91$ \\
\hline \multirow{8}{*}{$\begin{array}{l}\text { Severe sunburns } \\
\text { at }<15 \text { years of age }\end{array}$} & \multirow{4}{*}{ No } & Total & 49 & 68 & - & - & - \\
\hline & & $W_{t} / W_{t}$ & 35 (17) & $72(41)$ & - & Reference & - \\
\hline & & $W_{t} / V$ & 55 (27) & $27(18)$ & 0.0018 & 3.62 & $1.59-8.23$ \\
\hline & & $\mathrm{V} / \mathrm{V}$ & $10(5)$ & $1(1)$ & $0.016 \$$ & 12.06 & $1.17-583.78$ \\
\hline & \multirow{4}{*}{ Yes } & Total & 49 & 37 & - & - & - \\
\hline & & $W_{t} / W_{t}$ & $31(15)$ & $62(23)$ & - & Reference & - \\
\hline & & $W_{t} / \mathrm{V}$ & $47(23)$ & $27(10)$ & 0.011 & 3.53 & $1.31-9.46$ \\
\hline & & $\mathrm{V} / \mathrm{V}$ & $22(11)$ & $11(4)$ & 0.026 & 4.22 & $1.13-15.72$ \\
\hline \multirow{8}{*}{$\begin{array}{l}\text { Severe sunburns at } \\
\text { at }>15 \text { years of age }\end{array}$} & No & Total & 41 & 41 & - & - & - \\
\hline & & $W_{t} / W_{t}$ & $34(14)$ & $71(41)$ & - & Reference & - \\
\hline & & $W_{t} / \mathrm{V}$ & $56(23)$ & 26 (15) & 0.0007 & 4.49 & $1.85-10.93$ \\
\hline & & $\mathrm{V} / \mathrm{V}$ & $10(4)$ & $3(2)$ & $0.06 \$$ & 5.86 & $0.72-68.94$ \\
\hline & Yes & Total & 57 & 47 & - & - & - \\
\hline & & $W_{t} / W_{t}$ & $32(18)$ & $66(31)$ & - & Reference & - \\
\hline & & $\mathrm{Wt} / \mathrm{V}$ & $47(27)$ & $28(13)$ & 0.0004 & 3.58 & $1.48-8.63$ \\
\hline & & $V / V$ & $21(12)$ & $6(3)$ & 0.0036 & 6.89 & $1.71-27.72$ \\
\hline Holidays exposure at & High & Total & 86 & 84 & - & - & - \\
\hline at $<15$ years of age & & $W_{t} / W_{t}$ & $36(31)$ & $68(57)$ & - & Reference & - \\
\hline & & $\mathrm{Wt}_{t} / \mathrm{V}$ & $48(41)$ & $26(22)$ & 0.0003 & 3.43 & $1.74-6.75$ \\
\hline & & $\mathrm{V} / \mathrm{V}$ & $16(14)$ & $6(5)$ & 0.002 & 5.15 & $1.70-15.64$ \\
\hline Holidays exposure at & High & Total & 86 & 83 & - & & - \\
\hline at $>15$ years of age & & $W_{t} / W_{t}$ & $35(30)$ & $71(59)$ & - & Reference & - \\
\hline & & $\mathrm{Wt}_{t} / \mathrm{V}$ & $50(43)$ & $25(21)$ & $<0.0001$ & 4.03 & $2.04-7.97$ \\
\hline & & $\mathrm{V} / \mathrm{V}$ & $15(13)$ & $4(3)$ & 0.0004 & 8.52 & $2.25-32.23$ \\
\hline
\end{tabular}

variants, Asp84Glu and Asp294His alleles, that were previously associated with an important MM risk, ${ }^{8}{ }^{30}{ }^{31}$ were not

Table 7 *Statistical multiple analysis of MM risk factors

\begin{tabular}{lccl}
\hline Risk factor & $\mathbf{p}$ & OR & $\mathbf{9 5 \% ~ C l}$ \\
\hline Naevus count $>50$ & $<0.0001$ & 12.66 & $4.81-33.33$ \\
MCIR variant & $<0.0001$ & 4.52 & $2.15-9.52$ \\
Light eye colour & 0.007 & 3.11 & $1.49-6.49$ \\
Solar lentigines & 0.019 & 2.33 & $1.14-4.78$ \\
\hline
\end{tabular}

*Logistic regression multiple analysis includes all clinical risk factors and $M C I R$ variants, and was performed using a stepwise procedure. $\mathrm{OR}$, odds ratio; $\mathrm{Cl}, 95 \%$ confidence interval. here significantly associated with MM. This could probably be related to the size of our effectives, as their low frequency could have masked their effects on MM risk. We found no association with MM risk for the frequent variant Val92Met, in agreement with a previous report. ${ }^{31}$

There is a discrepancy concerning the effect of this substitution on MClR function. One study ${ }^{40}$ suggested that the Val92Met substitution reduced the binding affinity of $M C 1 R$ for $\alpha$-MSH, whereas another found that melanocytes homozygous for Val92Met responded dose dependently to $\alpha$-MSH with stimulation of cAMP formation, tyrosinase activity, and proliferation, suggesting that this polymorphism did not represent a loss of function of $\operatorname{MClR} .^{47}$ 
The PAR\% of MM associated with the main $M C 1 R$ variants (table 4) was much higher than that associated with CDKN2A mutations, which are very rare in most series of unselected melanoma. $^{50}$

The allelic frequency of $M C 1 R$ variants was the highest in MM patients with the most stringent genetic criteria (multiple and familial MM subgroups, table 5). However, our groups were too small to draw definitive conclusions, and we observed no statistical difference between the different MM subgroups; these results need to be assessed with a higher number of patients.

There is a debate as to whether the MCIR MM risk is independent or not of other melanoma clinical risk factors (skin type, mole count, and eye, hair, and skin colours). Initially, $M C 1 R$ variants were shown to increase MM risk only in individuals whose darker complexions would normally be considered protective, the association between MM and $M C I R$ variants disappearing in persons with light skins. ${ }^{8}$ More recently, the role of $M C I R$ was also demonstrated in individuals with skin types I and II and light hair colour in the Netherlands population. ${ }^{31}$ We further investigated whether the association between $M C I R$ variants and MM is independent of clinical risk factors in our French population, and showed the persistent effect of $M C 1 R$ variants on MM risk after stratification for the different clinical risk factors (table 6). This shows that $M C 1 R$ variants and pigmentary characteristics are independent $M M$ risk factors, and confirms and extends the results of the Dutch study. ${ }^{31}$ Furthermore, the effect of $M C I R$ variants also persists after stratification on UV exposure parameters, particularly in the absence of severe sunburns (table 6) that are classically considered to be important risk factors for melanoma formation. $^{51}$

The exact mechanisms underlying the increased risk to individuals carrying $M C I R$ variants of developing $M M$ are not known. First, recent investigations suggest that the quality of melanin, rather than its quantity, determines skin cancer risk. $^{52}$ In fact, increase of red yellow phaeomelanin in $M C 1 R$ variant melanocytes could contribute to mutagenesis and confer susceptibility to MM and non-melanoma skin cancer by generating free radicals following UV exposure. In addition, melanocytes with non-functional MCIR exhibit a pronounced increase of sensitivity to the cytotoxic effect of UV radiation compared with melanocytes expressing functional $M C 1 R^{47}$

Secondly, MCIR variants could affect some UV induced cellular protective effects. The cell cycle inhibitor pl6 $6^{\text {INK4a }}$ that plays a major role in genetic predisposition to familial melanoma and sporadic MM formation, appears to have an important role in a cell cycle checkpoint in skin after UV exposure..$^{53}$ As it has been shown that this UV epidermal induction of $\mathrm{pl}^{\mathrm{INK} 4 \mathrm{~A}}$ is induced by $\alpha \mathrm{MSH}$ via $M C 1 R^{55}$ the presence of $M C I R$ variants could alter this effect, thereby reducing its tumour suppressor function and providing a physiopathological basis for the formation of melanoma cells An additional hypothesis is that UV irradiation, in the presence of $M C 1 R$ variants, induces an important oxidative stress with formation of reactive oxygen species that have been shown to lead to a decrease of interaction between pl6 $6^{\mathrm{INK} 4 \mathrm{~A}}$ and $C d k 4$ proteins, thus promoting carcinogenesis. ${ }^{56}$

Thirdly, in our study, $M C 1 R$ variants were also present in $57 \%$ of patients with non-photo induced melanoma, further suggesting that MCIR could act on MM risk via nonpigmentary mechanisms. One of these mechanisms could be an autocrine effect of $\alpha$-MSH on melanoma cells. It has recently been demonstrated that $\alpha$-MSH significantly reduces the growth and progression (via decreasing fibronectin binding) of wild type MCIR melanoma cells, but has no effect on melanoma cells with $M C 1 R$ variants. ${ }^{57}$
Finally, we showed that in multiple logistic regression analysis taking into account all MM clinical and genetic risk factors, $M C 1 R$ variants were identified as the second MM risk factor following a high naevus count (table 7). This result inclines us to consider the $M C 1 R$ genotype to be an important MM marker risk, at least equal to eye colour, hair colour, or skin type in MM risk evaluation.

In conclusion, we have shown that carrying particular $M C 1 R$ variants increases MM risk in France. The association between MM and MCIR variants persists once skin, hair, and eye colours, skin type, mole count, and AMS phenotypes are taken into account. In addition, MCIR variants were identified as the second MM risk factor following a high naevus count. If our data could be confirmed in larger series, this would suggest that assessing $M C 1 R$ status, in association with clinical risk factors, might be useful in identifying high risk groups to be targeted for prevention.

\section{ACKNOWLEDGEMENTS}

This work was supported by grants from L'Assistance Publique des Hôpitaux de Paris and from La Société Française de Dermatologie.

\section{Authors' affiliations}

E Matichard, R Meziani, B Gérard, G Bertrand, B Grandchamp, N Soufir, Laboratoire de Biochimie Hormonale et Génétique, Hôpital Bichat-Claude Bernard, Paris, France

P Verpillat, Département d'Epidémiologie, de Biostatistiques et de Recherche Clinique, Hôpital Bichat-Claude Bernard, Paris, France V Descamps, E Legroux, M Burnouf, F Bouscarat, C Picard, B Crickx, Service de Dermatologie, Hôpital Bichat-Claude Bernard, Paris, France A Archimbaud, L Ollivaud, N Basset-Seguin, D Kerob, C Lebbe, Service de Dermatologie, Hôpital Saint-Louis, Paris, France

G Lanternier, Service de Dermatologie, Hôpital Percy, Clamart, France

Correspondence to: N Soufir, Laboratoire de Biochimie Hormonale et Génétique, Hôpital Bichat-Claude Bernard, 46 rue Henri Huchard, 75018 Paris, France; nsoufir@yahoo.com

\section{REFERENCES}

1 Dreno B, Wallon-Dumont G. Epidemiology of melanoma. Presse Med 2003:32(1):30-2.

2 Bliss JM, Ford D, Swerdlow AJ, et al. Risk of cutaneous melanoma associated with pigmentation characteristics and freckling: systematic overview of 10 case-control studies. The International Melanoma Analysis Group (IMAGE). Int J Cancer 1995:62(4):367-76.

3 Kamb A, Shattuck-Eidens D, Eeles R, et al. Analysis of the p16 gene (CDKN2) as a candidate for the chromosome 9p melanoma susceptibility locus. Nat Genet 1994;8(1):23-6.

4 Hussussian CJ, Struewing JP, Goldstein AM, et al. Germline p16 mutations in familial melanoma. Nat Genet 1994;8(1):15-21.

5 Zuo L, Weger J, Yang Q, et al. Germline mutations in the p16INK4a binding domain of CDK4 in familial melanoma. Nat Genet 1996;12(1):97-9.

6 Holland EA, Schmid H, Kefford RF, et al. CDKN2A (P16(INK4a)) and CDK4 mutation analysis in 131 Australian melanoma probands: effect of family history and multiple primary melanomas. Genes Chromosomes Cancer 1999;25(4):339-48

7 Winsey SL, Haldar NA, Marsh HP, et al. A variant within the DNA repair gene XRCC 3 is associated with the development of melanoma skin cancer. Cancer $\operatorname{Res} 2000 ; 60(20): 5612-16$

8 Palmer JS, Duffy DL, Box NF, et al. Melanocortin-1 receptor polymorphisms and risk of melanoma: is the association explained solely by pigmentation phenotype? Am J Hum Genet 2000;66(1):176-86.

9 Kanetsky PA, Holmes R, Walker A, et al. Interaction of glutathione Stransferase $\mathrm{MI}$ and $\mathrm{T} 1$ genotypes and malignant melanoma. Cancer Epidemiol Biomarkers Prev 2001;10(5):509-13.

10 Strange RC, Ellison T, Ichii-Jones F, et al. Cytochrome P450 CYP2D6 genotypes: association with hair colour, Breslow thickness and melanocyte stimulating hormone receptor alleles in patients with malignant melanoma. Pharmacogenetics 1999:9(3):269-76.

11 Bastiaens M, ter Huurne J, Gruis N, et al. The melanocortin-1-receptor gene is the major freckle gene. Hum Mol Genet 2001;10(16):1701-8.

12 Valverde $\mathbf{P}$, Healy $E$, Jackson I, et al. Variants of the melanocyte-stimulating hormone receptor gene are associated with red hair and fair skin in humans. Nat Genet 1995; 11(3):328-30.

13 Kennedy C, ter Huurne J, Berkhout M, et al. Melanocortin 1 receptor (MCIR) gene variants are associated with an increased risk for cutaneous melanoma which is largely independent of skin type and hair color. J Invest Dermatol $2001 ; 117(2): 294-300$. 
14 Chhajlani V. Distribution of cDNA for melanocortin receptor subtypes in human tissues. Biochem Mol Biol Int 1996;38(1):73-80.

15 Abdel-Malek Z, Scott MC, Suzuki I, et al. The melanocortin-1 receptor is a key regulator of human cutaneous pigmentation. Pigment Cell Res 2000;8:156-62.

16 Yang YK, Ollmann MM, Wilson BD, et al. Effects of recombinant agoutisignaling protein on melanocortin action. Mol Endocrinol 1997; 1 1 (3):274-80.

17 Kanetsky PA, Swoyer J, Panossian S, et al. A polymorphism in the agouti signaling protein gene is associated with human pigmentation. Am J Hum Genet 2002;70(3):770-5

18 Box NF, Wyeth JR, O'Gorman LE, et al. Characterization of melanocyte stimulating hormone receptor variant alleles in twins with red hair. Hum Mol Genet 1997:6(11):1891-7

19 Smith R, Healy E, Siddiqui S, et al. Melanocortin 1 receptor variants in an Irish population. J Invest Dermatol 1998;111(1):119-22.

20 Sturm RA, Teasdale RD, Box NF. Human pigmentation genes: identification, structure and consequences of polymorphic variation. Gene 2001;277 (1-2):49-62.

21 Schaffer JV, Bolognia JL. The melanocortin-1 receptor: red hair and beyond. Arch Dermatol 2001;137(11):1477-85.

22 Frandberg PA, Doufexis $M$, Kapas $S$, et al. Human pigmentation phenotype: a point mutation generates nonfunctional MSH receptor. Biochem Biophys Res Commun 1998;245(2):490-2.

23 Schioth HB, Phillips SR, Rudzish R, et al. Loss of function mutations of the human melanocortin 1 receptor are common and are associated with red hair. Biochem Biophys Res Commun 1999;260(2):488-91.

24 Jimenez-Cervantes C, Olivares C, Gonzalez P, et al. The Prol 62 variant is a loss-of-function mutation of the human melanocortin 1 receptor gene. J Invest Dermatol 2001;117(1):156-8.

25 Jimenez-Cervantes C, Germer S, Gonzalez P, et al. Thr40 and Met1 22 are new partial loss-of-function natural mutations of the human melanocortin 1 receptor. FEBS Lett 2001;508(1):44-8.

26 Healy $\mathrm{E}$, Jordan SA, Budd PS, et al. Functional variation of $M C 1 R$ alleles from red-haired individuals. Hum Mol Genet 2001;10(21):2397-402.

27 Healy E, Flannagan N, Ray A, et al. Melanocortin-1-receptor gene and sun sensitivity in individuals without red hair. Lancet 2000;355(9209):1072-3.

28 Flanagan N, Healy E, Ray A, et al. Pleiotropic effects of the melanocortin 1 receptor $(M C 1 R)$ gene on human pigmentation. Hum Mol Genet 2000;9(17):2531-7.

29 Sturm RA. Skin colour and skin cancer $-M C 1 R$, the genetic link. Melanoma Res 2002;12(5):405-16.

30 Valverde $\mathbf{P}$, Healy E, Sikkink S, et al. The Asp84Glu variant of the melanocortin 1 receptor $(M C 1 R)$ is associated with melanoma. Hum Mol Genet 1996;5(10):1663-6.

31 Kennedy C, ter Huurne J, Berkhout $M$, et al. Melanocortin 1 receptor (MC1R) gene variants are associated with an increased risk for cutaneous melanoma which is largely independent of skin type and hair color. J Invest Dermatol $2001 ; 117(2): 294-300$.

32 Bastiaens MT, Huurne JA, Kielich C, et al. Melanocortin-1 receptor gene variants determine the risk of nonmelanoma skin cancer independently of fair skin and red hair. Am J Hum Genet 2001;68(4):884-94.

33 Box NF, Duffy DL, Irving RE, et al. Melanocortin-1 receptor genotype is a risk factor for basal and squamous cell carcinoma. J Invest Dermatol $2001 ; 116(2): 224-9$

34 Jones Fl, Ramachandran S, Lear J, et al. The melanocyte stimulating hormone receptor polymorphism: association of the $\mathrm{V} 92 \mathrm{M}$ and $\mathrm{A} 294 \mathrm{H}$ alleles with basal cell carcinoma. Clin Chim Acta 1999;282(1-2):125-34.
35 Box NF, Duffy DL, Chen W et al. MC1R genotype modifies risk of melanoma in families segregating CDKN2A mutations. Am J Hum Genet 2001;69:4.

36 van Der Velden PA, Sandkuijl LA, Bergman W, et al. Melanocortin-1 receptor variant R151C modifies melanoma risk in Dutch families with melanoma. Am J Hum Genet 2001;69:4.

37 Saida T. Recent advances in melanoma research. J Dermatol Sci $2001 ; 26(1): 1-13$

38 Kato T, Suetake T, Sugiyama $Y$, et al. Epidemiology and prognosis of subungual melanoma in 34 Japanese patients. $\mathrm{Br} J$ Dermato 1996:134(3):383-7.

39 Newton JA, Bataille V, Griffiths K, et al. How common is the atypical mole syndrome phenotype in apparently sporadic melanoma? J Am Acad Dermatol 1993;29(6):989-96.

40 Xu X, Thornwall M, Lundin LG, et al. Val92Met variant of the melanocyte stimulating hormone receptor gene. Nat Genet 1996;14(4):384.

41 Mas JS, Sanchez CO, Ghanem G, et al. Loss-of-function variants of the human melanocortin-1 receptor gene in melanoma cells define structural determinants of receptor function. Eur J Biochem 2002;269(24):6133-41.

42 Rana BK, Hewett-Emmett D, Jin L, et al. High polymorphism at the human melanocortin 1 receptor locus. Genetics 1999;151(4):1547-57.

43 Smith AG, Box NF, Marks LH, et al. The human melanocortin-1 receptor locus: analysis of transcription unit, locus polymorphism and haplotype evolution. Gene 2001;281(1-2):81-94.

44 Harding RM, Healy E, Ray AJ, et al. Evidence for variable selective pressures at MCIR. Am J Hum Genet 2000;66(4):1351-61.

45 Bastiaens MT, ter Huurne JA, Kielich C, et al. Melanocortin-1 receptor gene variants determine the risk of nonmelanoma skin cancer independently of fair skin and red hair. Am J Hum Genet $2001 ; 68(4): 884-94$

46 Flanagan N, Ray AJ, Todd C, et al. The relation between melanocortin 1 receptor genotype and experimentally assessed ultraviolet radiation sensitivity. J Invest Dermatol 2001;117(5):1314-17.

47 Scott MC Wakamatsu K, Ito $S$, et al. Human melanocortin 1 receptor variants, receptor function and melanocyte response to UV radiation. J Cell Sci 2002; 115(11):2349-55

48 Bruzzi P, Green SB, Byar DP, Brinton LA, Schairer C. Estimating the population attributable risk for multiple risk factors using case-control data. Am J Epidemiol 1985;122(5):904-14.

49 Jackson IJ. Homologous pigmentation mutations in human, mouse and other model organisms. Hum Mol Genet 1997;6(10):1613-24.

50 Aitken J, Welch J, Duffy D, Milligan A, Green A, Martin N, Hayward N. J Natl Cancer Inst 1999:91:446-52.

51 Langley RG, Sober AJ. A clinical review of the evidence for the role of ultraviolet radiation in the etiology of cutaneous melanoma. Cancer Invest 1997; 15(6):561-7.

52 Wikberg JE, Muceniece R, Mandrika I, et al. New aspects on the melanocortins and their receptors. Pharmacol Res 2000:42(5):393-420.

53 Milligan A, Gabrielli BG, Clark JM, et al. Involvement of p16CDKN2A in cell cycle delays after low dose UV irradiation. Mutat Res 1998;422(1):43-53.

54 Pavey S, Conroy S, Russell T, et al. Ultraviolet radiation induces p16CDKN2A expression in human skin. Cancer Res 1999:59(17):4185-9.

55 Pavey S, Gabrielli B. Alpha-melanocyte stimulating hormone potentiates pl6/ CDKN2A expression in human skin after ultraviolet irradiation. Cancer Res 2002;62(3):875-80.

56 Martin EA, Robinson PJ, Franklin RA. Oxidative stress regulates the interaction of pl6 with Cdk4. Biochem Biophys Res Commun 2000;275(3):764-7.

57 Robinson SJ, Healy E. Human melanocortin 1 receptor $(M C 1 R)$ gene variants alter melanoma cell growth and adhesion to extracellular matrix. Oncogene 2002;21(52):8037-46 